\section{Produção e caracterização de uma liga Fe-Ni obtida por processamento coloidal aquoso e reação de estado sólido}

Luiz Eloi Vieira Junior ${ }^{1}$, João Batista Rodrigues Neto ${ }^{1}$ Aloísio Nelmo Klein ${ }^{1}$, Dachamir Hotza ${ }^{2}$, Rodrigo Moreno ${ }^{3}$

\author{
${ }^{1}$ Laboratório Interdisciplinar de Materiais (Labmat), Departamento de Engenharia Mecânica (EMC), Universidade \\ Federal de Santa Catarina (UFSC), Campus Universitário Trindade,88040-900Florianópolis, SC \\ ${ }^{2}$ Núcleo de Materiais Cerâmicos e Compósitos (Cermat), Departamento de Engenharia Química (EQA), Universidade \\ Federal de Santa Catarina (UFSC), Campus Universitário Trindade, 88040-900 Florianópolis, SC \\ e-mail: dhotza@gmail.com \\ ${ }^{3}$ Instituto de Cerámica y Vidrio (ICV/CSIC), Kelsen 5 Kelsen 5, Campus de Cantoblanco, 28049, Madri, Espanha \\ e-mails: eloi_junior@hotmail.com,jbrn.ufsc@gmail.com, a.n.klein@ufsc.br, d.hotza@ufsc.br, rmoreno@icv.csic.es
}

\section{RESUMO}

O processamento coloidal é uma técnica amplamente usada para a produção de componentes cerâmicos. Diversos artigos científicos foram publicados na última década apresentando a possibilidade de se obter suspensões aquosas concentradas estáveis de partículas metálicas a partir do seu controle de pH e uso de dispersantes. Este artigo tem o objetivo de estudar a produção de um aço com microestrutura austenítica usando pós elementares de ferro (Fe) e níquel (Ni) via rota coloidal. Para tanto, foram realizadas medições de potencial zeta entre os pHs 2 e 12 para a composição Fe30Ni em massa. As suspensões aquosas atingiram concentrações de sólidos de até $45 \% \mathrm{v} / \mathrm{v}$ e processadas por colagem de barbotina. Os compactados colados foram caracterizados por densidade (Arquimedes), análise térmica diferencial (ATD) e dilatometria. Após a sinterização aos $900^{\circ} \mathrm{C}$ e $1100^{\circ} \mathrm{C} / 1 \mathrm{~h}$, os compactados apresentaram microestrutura com formação de maclas de recozimento, porosidade inferior a $10 \%$ em volume e microdureza Vickers aproximada de $160 \mathrm{HV}$.

Palavras-chave: Reologia, ligas metálicas e colagem de barbotina.

\section{ABSTRACT}

Colloidal processing is a widely used technique to produce ceramic components. Several papers have been published in the last decade presenting the possibility to obtain aqueous concentrate stable suspension of metallic particles from their $\mathrm{pH}$ control and using dispersants. This paper aims to study the production of a steel with austenitic microstructure using elemental iron $(\mathrm{Fe})$ and nickel (Ni) powders via colloidal route. For this, Zeta potential measurements were performed between $\mathrm{pH} 2$ and 12 to $\mathrm{Fe} 30 \mathrm{Ni}$ wt $\%$ composition. Aqueous suspensions reached solids concentrations of up to $45 \% \mathrm{v} / \mathrm{v}$ and processed by slip casting. The compacts were characterized by density (Archimedes), differential thermal analysis (DTA) and dilatometry. After sintering at $900^{\circ} \mathrm{C}$ to $1100^{\circ} \mathrm{C} / 1 \mathrm{~h}$, the sintered bodies presented a microstructure with of annealing twins, porosity less than $10 \% \mathrm{v} / \mathrm{v}$ approximate Vickers microhardness of $160 \mathrm{HV}$.

Keywords: Rheology, metal alloys, slip casting.

\section{INTRODUÇÃO}

Nos anos recentes, pesquisadores tem se dedicado em estudar a dispersão e estabilização de suspensões aquosas composta por partículas metálicas como uma rota alternativa de processo de fabricação de materiais metálicos e compósitos sinterizados. O desafio da aplicação desta rota de processamento situa-se na dificuldade de se manter dispersas e suspensas partículas metálicas, devido à sua densidade elevada em comparação aos materiais cerâmicos e a alta reatividade com a água que resulta na sedimentação da fase sólida. $[1,2]$

O primeiro material de que alavancou as pesquisas neste tema foi o níquel no início dos anos 2000, focado em uma nova rota de produção de ânodos para células a combustível, recobrimentos e compósitos estruturais metal-cerâmica. [1-3] Subsequentemente, Lussoli et al [4] conduziram um estudo de dispersão de pós de ferro em meio aquoso para produzir compactados para atuar como veículos para nanopartículas 
cerâmicas aplicadas na indústria de fundição de ferros fundidos cinzentos.

Conceitualmente, quando um metal é exposto ao ar atmosférico, rapidamente forma-se uma fina camada de poucos nanômetros de óxido que se estabiliza. Logo, a interação com a água altera as condições de superfície em função do $\mathrm{pH}$ do meio. Hernandez [1] e coautores publicaram um trabalho com pós de níquel. Em valores de $\mathrm{pH}$ ácidos, as superfícies das partículas corroíam e dissolviam-se na forma de $\mathrm{Ni}^{+2}$. Por outro lado, quando os pós entravam em contato com o meio básico, mais precisamente em $\mathrm{pH}$ superior ao 9 , formava-se uma camada passivada de $\mathrm{NiO}(\mathrm{OH})_{2}$. Sendo assim, a produção de suspensões composta por partículas metálicas requer ajuste do $\mathrm{pH}$ para valores básicos para que esta camada possa ser facilmente eliminada durante a sinterização em atmosfera redutora, mantendo a integridade do compactado.

A estabilidade das suspensões é alcançada a partir do qual as forças de repulsão entre as partículas se sobressaem sobre as forças de atração de van der Waals. Essa condição pode ser alcançada de três maneiras: repulsão eletrostática, estérica ou uma combinação de ambas (eletroestérica). Em particular, a repulsão eletrostática consiste na manutenção das partículas em suspensão num meio líquido polar (água ou solvente orgânico) através do desenvolvimento de uma nuvem iônica ou dupla camada elétrica. Isto proporciona uma série de benefícios de processamento, como a obtenção de suspensões altamente concentradas, gerando peças com menor retração durante a secagem. Consequentemente, após a sinterização será alcançada uma microestrutura mais homogênea e um componente com melhores propriedades mecânicas. Portanto, conceitos sobre reologia constituem uma ferramenta poderosa para avaliar a estabilidade das suspensões. As medições de curvas de fluxo são importantes para determinar, por exemplo, o melhor dispersante e suas concentrações para obter suspensões mais fluidas possíveis para facilitar as diversas etapas posteriores como moagem, bombeamento e colagem em molde. [5]

A microestrutura típica para uma liga Fe-Ni é a austenítica, devido ao fato que o níquel se estabelece como solução sólida solução sólida substitucional dentro da estrutura cristalina do ferro via processos difusivos assistidos pela temperatura e estabiliza a estrutura cúbica de faces centradas (CFC) na temperatura ambiente. De acordo com a composição química, as ligas Fe-Ni também são suscetíveis ao endurecimento por deformação plástica com a formação de uma microestrutura martensítica. As ligas Fe-Ni possuem diversas aplicações tecnológicas como para materiais magnéticos moles, os quais requerem alta permeabilidade magnética, baixa perda por histerese e baixa temperatura de transição Curie. O níquel dentro da liga apresenta um efeito sobre o coeficiente de expansão térmica que pode abranger valores da ordem de 0,5 a $20 \mu \mathrm{m} /(\mathrm{m} \cdot \mathrm{K})$. Usualmente, esses materiais são produzidos por conformação mecânica, como laminação e trefilação. [6-8]

Uma rota alternativa à conformação mecânica de componentes a base de ligas Fe-Ni é a metalurgia do pó, que apresenta algumas vantagens como melhor aproveitamento da matéria-prima e controle microestrutural. Os processos mais conhecidos são a prensagem e a moldagem de pós por injeção. Nesses processos, podem ser obtidas peças densas ou porosas para diversas aplicações mecânicas, tribológicas, elétricas, entre outras. A moldagem de pós por injeção (ou PIM, do inglês Powder Injection Molding) permite produzir peças com dimensões reduzidas e com geometrias complexas, com alta produtividade, reprodutibilidade e sem necessidade de uma etapa de acabamento. [9-12] Contudo, para a produção da mistura para injeção são necessárias altas concentrações de polímeros $(15-50 \% \mathrm{v} / \mathrm{v})$ que demandam controle tanto das propriedades reológicas, dadas suas elevadas viscosidades $(10-1000 \mathrm{Pa.s})$ e tratamentos térmicos demorados para sua extração e posterior sinterização das peças.[2]

Dentro desde contexto, o objetivo deste trabalho é apresentar uma rota alternativa de processamento via metalurgia do pó, através de um estudo reológico, e produzir a partir de reações de estado sólido uma liga ferrosa com microestrutura austenítica pela rota coloidal aquosa.

\section{MATERIAIS E MÉTODOS}

Para este trabalho foram utilizados pós comerciais de níquel (Inco T-110, Canadá) e ferro (Diafe 2000, Alemanha) com tamanhos médios de partículas de 2,5 e 1,6 $\mu \mathrm{m}$ respectivamente e densidades de 8,7 para os pós de $\mathrm{Ni}$ e $7,6 \mathrm{~g} / \mathrm{cm}^{3}$ para os pós de ferro. A combinação destes dados resulta no valor de densidade teórica de misturas de $7,9 \mathrm{~g} / \mathrm{cm}^{3}$. As medições das curvas de potencial Zeta para os pós de ferro, níquel e a mistura $\mathrm{Fe} 30 \mathrm{Ni}$ foram obtidas a partir da técnica de velocimetria Doppler com equipamento Zetasizer (NanoZS, Malvern, Reino Unido). Para tanto, foram preparadas suspensões diluídas com concentração de sólidos de 0,1 $\mathrm{g} / \mathrm{l}$ dispersas numa solução aquosa, de $10^{-3} \mathrm{M} \mathrm{KCl}$ para facilitar a mobilidade eletroforética com aplicação de homogeneização via sonda ultrassônica com potência de 400W (Hielscher UP400S, Alemanha) durante 1 min. Na determinação dos valores de $\mathrm{pH}$ usaram-se soluções de $\mathrm{HCl}$ e $\mathrm{KOH} 10^{-1} \mathrm{M}$. Suspensões aquosas da mistura Fe30Ni em concentrações de sólidos crescentes de 30, 40 e $45 \% \mathrm{v} / \mathrm{v}$. As suspensões foram 
estabilizadas com dispersante poliacrilato de amônio (Duramax D-3005, Rohm and Haas, EUA). As concentrações de dispersante foram determinadas de acordo com seus valores individuais, sendo $2,0 \% \mathrm{~m} / \mathrm{m}$ para o $\mathrm{Fe}$ [4] e $0,6 \% \mathrm{~m} / \mathrm{m}$ para o $\mathrm{Ni}$ [2] com adição de tetrametil hidróxido de amônio e conduzindo o $\mathrm{pH}$ para 10. Todas as diluições para caracterizações das partículas e produção das suspensões usaram-se água deionizada. A caracterização reológica foi conduzida usando um reômetro RS50 (Haake, Alemanha) com sensor cone/placa (DC60/2 $2^{\circ}$, Haake, Alemanha) com temperatura de teste em $25^{\circ} \mathrm{C}$. As curvas de fluxo foram medidas através de taxa de cisalhamento constante (control rate, $\mathrm{CR}$ ). Para se atingir alto cisalhamento, os experimentos foram realizados empregando um programa dividido em três estágios: uma rampa linear de cisalhamento de $0-1000 \mathrm{~s}^{-1}$ em $3 \mathrm{~min}$; um patamar no cisalhamento máximo por $30 \mathrm{~s}$ e 1000 $-0 \mathrm{~s}^{-1}$ por $3 \mathrm{~min}$. Ao final dos ensaios, foram testados três modelos reológicos de ajuste das curvas: Casson, Herschel-Bulkley e Bingham:

$$
\begin{aligned}
& \tau_{\text {Casson }}=\sqrt[n]{\left(\tau_{n}^{n}+\left(\gamma \eta_{p}\right)^{n}\right.} \\
& \tau_{H . B .}=\tau_{0}+K \cdot\left(\dot{\gamma}^{n}\right) \\
& \tau_{\text {Bingham }}=\tau_{0}+\eta \cdot \dot{\gamma}
\end{aligned}
$$

Os compactados colados verdes na composição Fe30Ni tiveram seus comportamentos de sinterização estudados por análise térmica diferencial STA (Netzsch STA 449F3, Alemanha) e dilatometria (Netzsch 402 EP, Germany) em atmosfera de fluxo de $\mathrm{Ar} / 5 \% \mathrm{H}_{2}$ até os $1200^{\circ} \mathrm{C}$ com taxa de $10^{\circ} \mathrm{C} / \mathrm{min}$. A sinterização foi realizada em dois estágios, com o primeiro patamar em $500^{\circ} \mathrm{C}$ por 40 min para eliminação do dispersante polimérico seguido da consolidação em duas temperaturas distintas: 900 e $1100^{\circ} \mathrm{C}$ durante $1 \mathrm{~h}$. As densidades foram medidas pelo método de Arquimedes. As amostras sinterizadas passaram por preparação metalográfica em lixas até grana 1200 com posterior polimento com alumina $1,0 \mu \mathrm{m}$ e atacadas com reagente Marble (10 $\mathrm{g} \mathrm{CuSO}_{4}, 50 \mathrm{ml} \mathrm{HCl}, 50 \mathrm{ml}$ água destilada). As microestruturas foram observadas com microscópio eletrônico de varredura (TM-3000, Philips, Holanda) emicrossonda EDS acoplada para a quantificação da composição química. As fases presentes foram identificadas por difração de raios $\mathrm{X}$ usando difratômetro X'Pert (Philips, Holanda) com radiação de $\mathrm{Cu}(\lambda=1.54 \AA)$, filtro de Ni em $0.02^{\circ}(2 \theta / \mathrm{s})$ de velocidade de varredura. A microdureza Vickers foi determinada usando microdurômetro (Shimadzu HMV2, Japão) com média obtida de 10 medições.

\section{RESULTADOS E DISCUSSÕES}

\subsection{Potencial zeta e comportamento reológico}

A Fig. 1 mostra as curvas de potencial zeta para as partículas de Fe e Ni, além da mistura para a liga Fe30Ni. Como foi descrito no trabalho de Lussoli et al. [4], as partículas de ferro apresentam um ponto de carga zero (PCZ) em $\mathrm{pH}$ próximo a 7,0. Por outro lado, as partículas de Ni tiveram seu PCZ em um valor de pH perto de 3,5. Esses valores mostram que as superfícies das partículas de ferro são levemente carregadas negativamente, ou seja, há presença de íons $(\mathrm{OH})^{-}$e as partículas de níquel estão mais fortemente carregadas, porém, por íons $\mathrm{H}^{+}$. Estes valores são muito próximos aos seus respectivos óxidos, demonstrando que nesta rota de processamento o que importa realmente é a interação entre a superfície e o meio líquido, que não considera se as partículas são metálicas ou de óxidos metálicos. [1,13] O valor resultante da mistura entre as partículas apresentou o PCZ perto de 6,5. A curva mostrou alguma influência das partículas de níquel. O maior valor de potencial deu-se no $\mathrm{pH} 10$, com intensidade perto dos $40 \mathrm{mV}$. Esse alto valor de potencial garante uma dupla camada elétrica suficientemente larga para impedir a aglomeração das partículas da suspensão. 


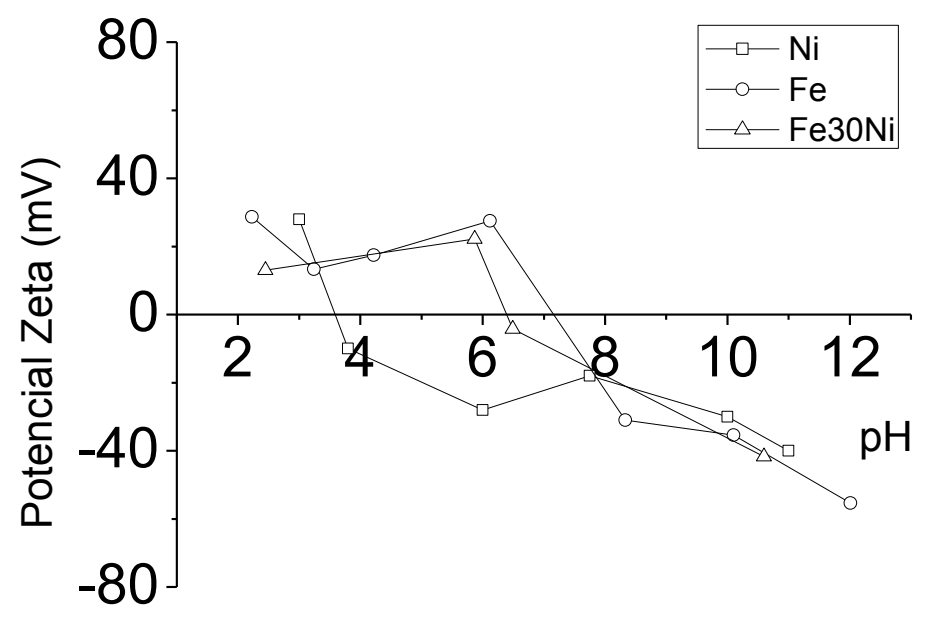

Figura 1: curvas de potencial zeta para pós de ferro, níquel e a mistura de pós na concentração fe30ni.

Suspensões aquosas concentradas na mistura Fe30Ni foram preparadas com concentrações crescentes de sólidos e suas curvas reológicas CR foram determinadas e mostradas na Fig. 2. Os resultados mostram que, em todas as concentrações de sólidos estudadas, o comportamento reológico foi do tipo pseudoplástico, com um gradual aumento na viscosidade conforme aumentada a fração de sólidos. Não foi identificada tixotropia, o que significa uma boa interação entre o dispersante e as partículas que promoveram a dispersão das partículas dentro do líquido. A suspensão com 30\% em volume de sólidos apresentou uma condição de fluidez muito baixa, indicando a possibilidade de se produzir suspensões ainda mais concentradas. Logo, aumentaram-se os teores de sólidos até os $45 \% \mathrm{v} / \mathrm{v}$ de sólidos. Apesar de se conseguir uma suspensão bem dispersa, como visto na sua curva de fluxo, a composição com melhores propriedades reológicas foi a com $40 \% \mathrm{v} / \mathrm{v}$ de sólidos, que também é uma suspensão bastante concentrada e com excelente fluidez para ser processada por colagem de barbotina. As curvas foram testadas segundo os modelos reológicos de Bingham, Casson e Herschel-Bulkley. Os resultados mostraram que, para todas as curvas, o modelo de HerschelBulkley produziu um os maiores coeficientes de determinação ( $\mathrm{R}^{2}$ superior a $\left.99 \%\right)$. Assim, a Tabela 1 relaciona as propriedades reológicas ajustadas em função da concentração de sólidos das suspensões.

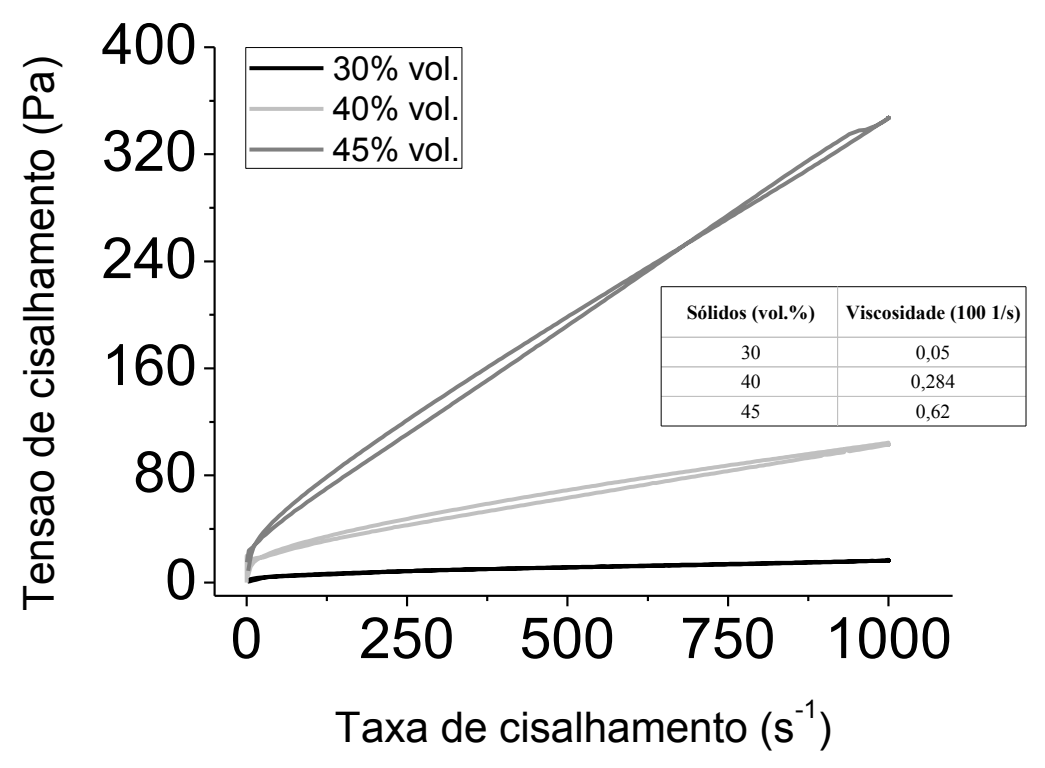

Figura 2: Curvas de fluxo e valores de viscosidades obtidas a partir das suspensões aquosas Fe30Ni para diferentes concentrações de sólidos. 
Tabela 1: Propriedades reológicas e correlações com o modelo de Hershel-Bulkley para as suspensões aquosas de Fe30Ni.

\begin{tabular}{|c|c|c|c|c|}
\hline $\begin{array}{l}\text { Sólidos } \\
(\% / \mathrm{v} / \mathrm{v})\end{array}$ & $\begin{array}{c}\text { Tixotropia } \\
(\mathrm{Pa} / \mathrm{s})\end{array}$ & Modelo reológico & $\begin{array}{c}\mathbf{R}^{2} \\
(\%) \\
\end{array}$ & $\begin{array}{c}\text { Tensão de escoamento } \\
(\mathbf{P a})\end{array}$ \\
\hline 30 & 211 & \multirow{3}{*}{ Herschel-Bulkley } & 99,76 & 2,23 \\
\hline 40 & 617 & & 99,94 & 10,22 \\
\hline 45 & 2808 & & 99,98 & 24,32 \\
\hline
\end{tabular}

A Fig. 3 mostra uma imagem do compactado colado verde Fe30Ni. Como é mostrado, ambos os pós elementares possuem morfologia quase esférica e com distribuição de tamanhos bem estreita, onde as partículas menores são as de ferro e as maiores correspondentes ao níquel. Com respeito às características reológicas, as suspensões produzidas a partir de partículas esféricas possuem maior concentração de sólidos, com comportamento reológico tipo pseudoplástico e muito bem dispersas pela ausência de tixotropia.

Quando a distribuição de tamanhos de partículas tem sua moda aumentada, com duas distribuições de tamanhos muito bem definidos, é possível formular suspensões concentradas bem dispersas. Isso produz, após a colagem, compactados verdes com elevadas densificações. Para o caso deste trabalho, os compactados colados verdes apresentaram um valor médio de densificação de $52 \%$ em relação à densidade teórica das misturas, que é um valor muito bom para peças metálicas processadas por colagem de barbotina.

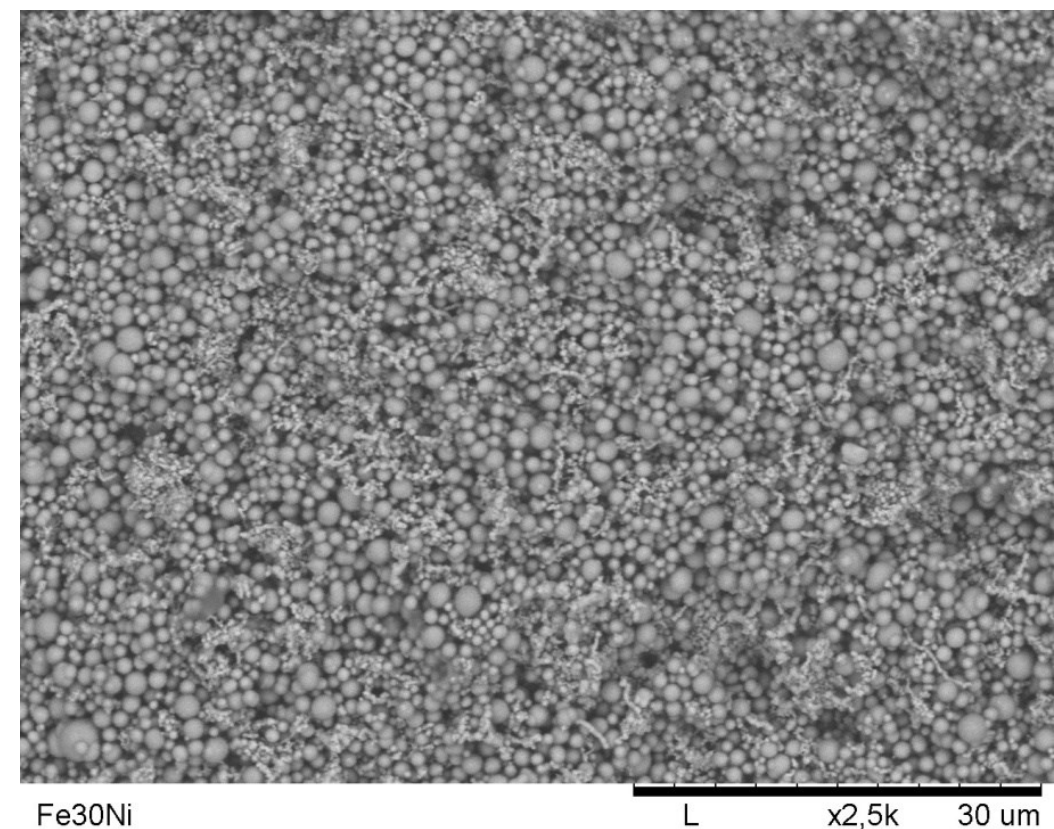

Figura 3: Micrografia de MEV da fratura do compactado colado a verde da suspensão com $40 \%$ em volume de sólidos.

\subsection{Análises térmicas e sinterizações}

A Fig. 4 mostra os resultados obtidos de análises térmica diferencial (ATD) e termogravimétrica (TG) para o compactado colado verde. A partir da curva de ATD percebe-se a presença de três regiões que cabe discussão. $\mathrm{O}$ primeiro pico de pouca intensidade energética identificado entre 300 e $400^{\circ} \mathrm{C}$ refere-se à eliminação de umidade adsorvida do ambiente, bem como a quantidades residuais da umidade presente no dispersante. Com o aquecimento, outro pico é identificado em aproximadamente $600^{\circ} \mathrm{C}$, é atribuído às reações de redução de camadas superficiais de óxidos metálicos de ferro e níquel. Entre 780 e $1070^{\circ} \mathrm{C}$ há a formação de um amplo pico que sugere a superposição de eventos térmicos. Para o caso das partículas de ferro, podem estar ocorrendo transformações de propriedades magnéticas (ponto Curie), além da mudança de estrutura cristalina $\mathrm{Fe}-\alpha / \mathrm{Fe}-\gamma$, bem como reações difusivas de estado sólido com as partículas de níquel 
estabilizando termodinamicamente a fase austenita. A termogravimetria mostra que houve uma perda de massa na temperatura mostrada relativa às reações de reduções, corroborando com a explicação anterior.

Acima desta faixa de temperaturas não foram identificados outros eventos térmicos significativos.

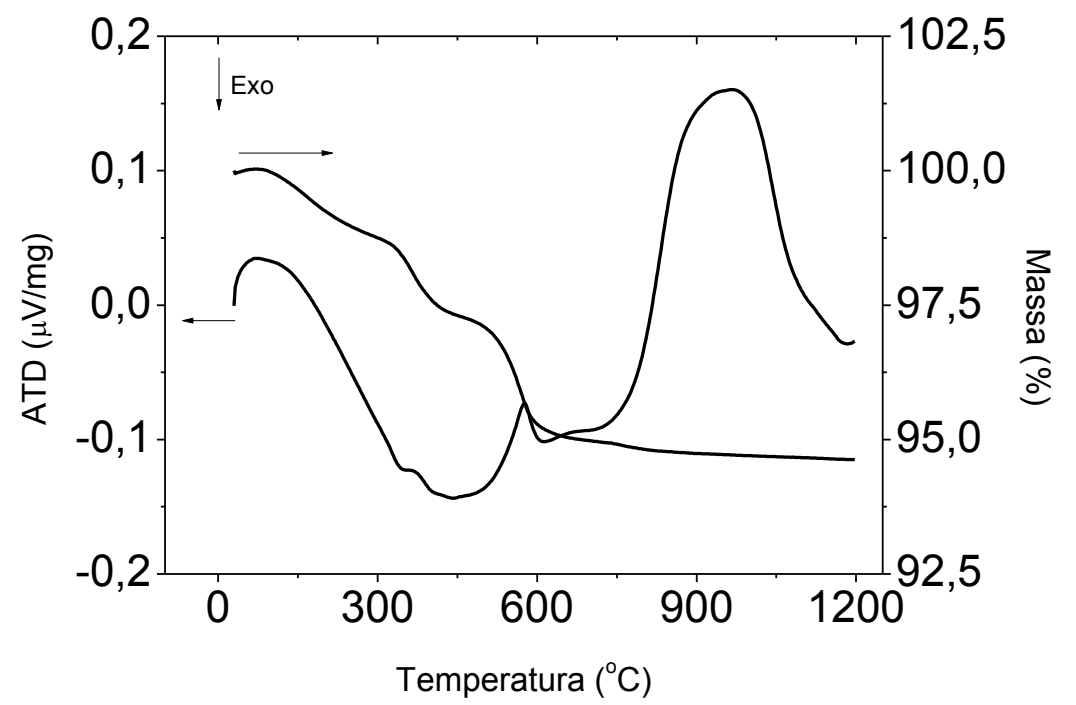

Figura 4: Curvas de ATD-TG para o compactado colado a verde de Fe30Ni em atmosfera de fluxo de $\mathrm{Ar} / 5 \% \mathrm{H}_{2}$.

A Fig. 5 mostra a curva resultante do ensaio de dilatometria e sua derivada para o compactado colado verde. Não há eventos térmicos significativos até os $550^{\circ} \mathrm{C}$, quando se inicia o processo de retração atingindo a maior taxa de densificação próximo aos $900^{\circ} \mathrm{C}$ e todo o processo de sinterização finaliza aos $1100^{\circ} \mathrm{C}$. A curva derivada da retração durante a sinterização mostra picos amplos devidos tanto à sinterização das partículas semelhantes de ferro e níquel bem como às reações difusivas entre os diferentes elementos, como mostrado anteriormente na curva de análise térmica diferencial. Com o término da sinterização, o compactado colado apresentou um valor de retração linear de $20 \%$. Isto pode ser explicado pela rota de processamento que promove valores mais elevados de retração, dado que a liberação de energia durante o processo se dá apenas pelo empacotamento das partículas. Outro fator importante é a presença dos mecanismos de difusão por efeito Kirkendall. Considerando esses resultados, as amostras foram submetidas à sinterização nas temperaturas de 900 e $1100^{\circ} \mathrm{C}$.

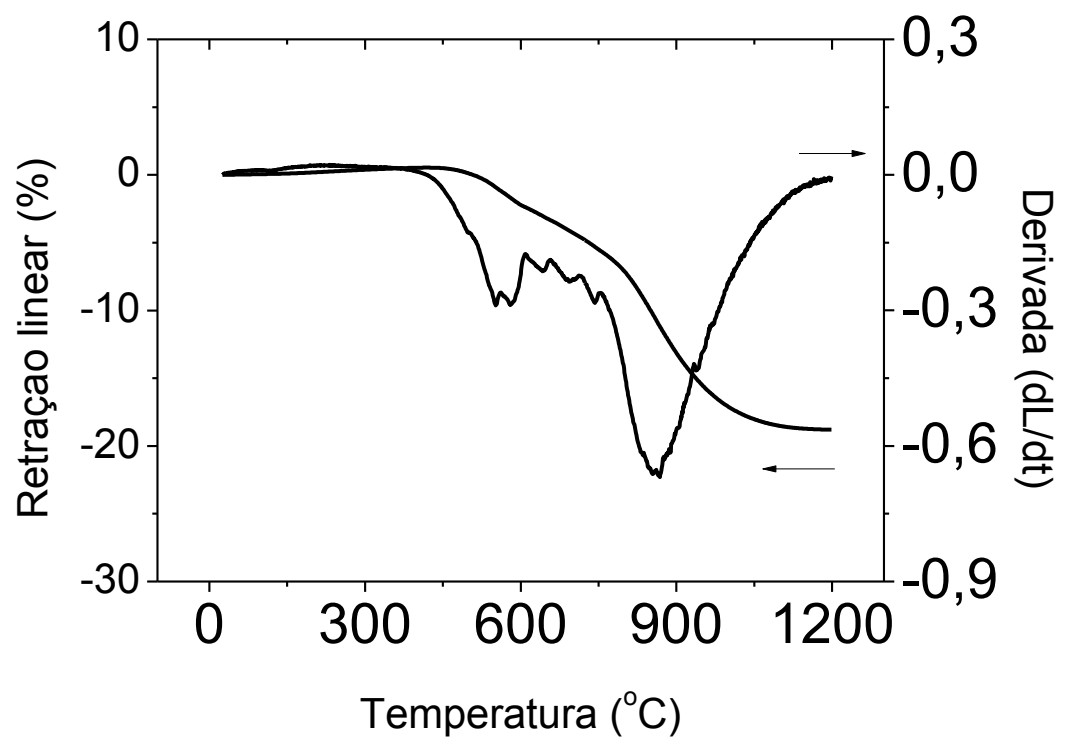

Figura 5: Curvas de dilatometria dinâmica e sua derivada para o compactado colado a verde de Fe30Ni em atmosfera de fluxo de $\mathrm{Ar} / 5 \% \mathrm{H}_{2}$.

A Fig. 6 mostra as microestruturas finais obtidas após a sinterização dos compactados colados a 900 e 
$1100^{\circ} \mathrm{C}$. Observam-se microestruturas muito similares, exibindo alguns tons de cinza devido a diferenças localizadas de composição química. Cabe ressaltar a formação de maclas de resfriamento, típica de estrutura cristalina do tipo cúbica de faces centradas (CFC), que significa a presença de austenita na temperatura ambiente. Foram realizadas medições de microanálise química por EDS. Os resultados mostram que houve boa distribuição do soluto por toda a matriz, graças aos tamanhos médios de partículas usados neste trabalho, o que facilitou a dissolução e a homogeneização durante a sinterização. Foram identificadas algumas ilhas de maiores concentrações tanto de ferro (fase acinzentada) quanto de níquel (fase clara). Essas ilhas são explicadas pela imagem da fratura do compactado colado verde, na qual foram identificados aglomerados de partículas de ferro envolvendo aglomerados de partículas de níquel.
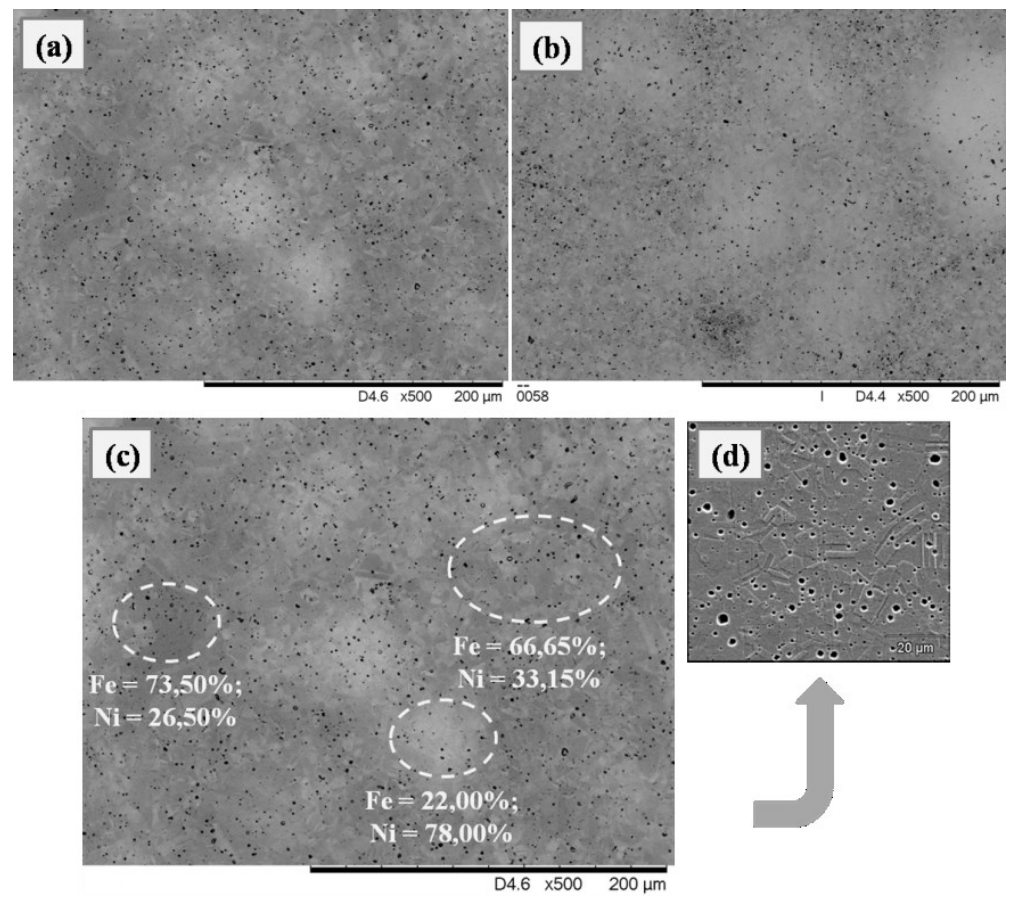

Figura 6: Micrografias de MEV das amostras $\mathrm{Fe} 30 \mathrm{Ni}$ sinterizadas por $1 \mathrm{~h}$ em atmosfera de fluxo de $\mathrm{Ar} / 5 \% \mathrm{H}_{2}$ ilustrada com resultados de microanálise química por EDS. Sendo: (a) 900 ; (b) $1100^{\circ} \mathrm{C}$; (c) resultados de microanálise química por EDS e; (d) maclas formadas durante o resfriamento.

Na Tabela 2 uma correlação entre as temperaturas de sinterização e os valores de microdureza Vickers dos compactados colados Fe30Ni. Como se observa, os compactados colados apresentaram valores semelhantes de densidades após a sinterização, independente da temperatura usada. Consequentemente, isso influenciou os valores medidos de microdureza. Em se tratando de pós metálicos elementares muito moles, era de se esperar pouco ganho de propriedades mecânicas. Neste caso, o pouco ganho de dureza foi apenas pela formação de solução sólida substitucional.

Tabela 2: Correlação entre temperaturas de sinterização e valores obtidos de microdureza Vickers.

\begin{tabular}{c|c|c|c}
\hline \multirow{2}{*}{ Temperatura de sinterização $\left({ }^{\circ} \mathrm{C}\right)$} & \multicolumn{2}{|c|}{ Densidade $\mathbf{( g / \mathbf { c m } ^ { \mathbf { 3 } } )}$} & Microdureza Vickers \\
\cline { 2 - 3 } & Verde & Sinterizado & $(\mathbf{H V})$ \\
\hline 900 & $4,1 \pm 0,6$ & $7,6 \pm 0,1$ & $150 \pm 5,0$ \\
\hline 1100 & $4,0 \pm 0,7$ & $7,7 \pm 0,2$ & $160 \pm 5,0$ \\
\hline
\end{tabular}

A Fig. 8 mostra os difratogramas das amostras de ferro, níquel e do sinterizado Fe30Ni. Os padrões de difração correspondem às seguintes cartas JCPDS: 00-006-0696 para os pós de ferro; 00-004-0850 para os pós de níquel; e 00-047-1405 para o material produzido. Essa última carta corresponde à fase $\mathrm{Fe}_{0.64} \mathrm{Ni}_{0.36}$. Não foram identificadas no difratograma do material sinterizado sobreposições de picos, nem de ferro e nem 
de níquel, mostrando que, durante a sinterização, praticamente todo o volume de material foi homogeneizado.

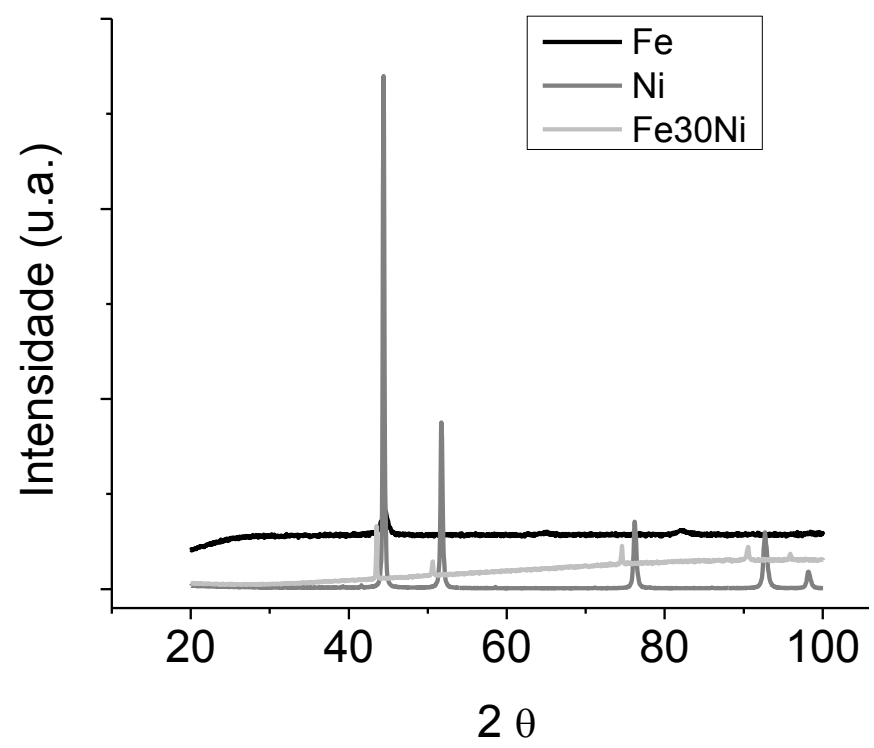

Figura 7: Difratogramas de DRX das amostras de Fe, Ni e da liga sinterizada Fe30Ni.

\section{CONCLUSÕES}

Este trabalho apresentou um estudo preliminar de produção de uma liga ferrosa Fe30Ni aplicando conhecimentos de reologia e processamento coloidal. Os resultados obtidos mostraram que as partículas de níquel interferiram na curva resultante de potencial zeta. A melhor concentração de sólidos para a produção das suspensões foi de $40 \% \mathrm{v} / \mathrm{v}$. O melhor modelo de ajuste das curvas reológicas foi o de Herschel-Bulkley.

Os compactados colados sinterizados não apresentaram alterações significativas quanto as densidades, bem como nos valores obtidos de microdureza Vickers. Por fim, os resultados de difração de raios-X e de microscopia confirmaram a boa homogeneização das matérias-primas para a produção da liga.

\section{AGRADECIMENTOS}

Os autores agradecem à CAPES e ao CNPq pelo apoio financeiro dado ao trabalho.

\section{BIBLIOGRAFIA}

[1] HERNÁNDEZ, N., MORENO, R., SÁNCHEZ-HERÊNCIA, A. J., et al. "Surface behavior of nickel powders in aqueous suspensions”, Journal of Physical Chemistry B , v. 109, pp. 4470-4474, 2005.

[2] SÁNCHEZ-HERÊNCIA, A. J., MILlÁN, A. J., NIETO, M. I., et al., "Aqueous Colloidal Processing of the Nickel Powder", Acta Materialia, v. 49, p. 645-651, 2001.

[3] FERRARI, B., SÁNCHEZ-HERÊNCIA, A. J., MORENO, R. "Nickel-alumina graded coating obtained by dipping and EPD on nickel substrates", Journal of the European Ceramic Society, v. 56, pp. 2205-2212, 2006.

[4] LUSSOLI, R. J., RODRIGUES NETO, J.B., KLEIN, A.N., et al., "Aqueous colloidal processing of carriers for delivering silica nanoparticles in iron matrix nanocomposites", Materials Research Bulletin , v. 48 , pp. 2430-2436, 2013.

[5] MÜllER, F., PEUKERT, W., POLKE, R., et al., "Dispersing nanoparticles in liquids", International Journal of Mineral Processing, v. 74S, pp. S31-S41, 2004.

[6] ASM. "Special-Purpose Nickel Alloys", In: ASM Specialty Handbook: nickel, cobalt, and their alloys. [S.1.]: ASM International, pp. 92-101, 2000.

[7] $\mathrm{M}_{\mathrm{C}}$ CREA, J. L., PALUMBO, G., HIBBARD, G.D., et al., "Properties and applications for electrodeposited nanocrystalline Fe-Ni alloys", Reviews on Advanced Materials Science, v. 5, pp. 252-258, 2003.

[8] SINNECKER, J. P. "Materiais magnéticos doces e materiais ferromagnéticos amorfos", Revista Brasileira de Ensino de Física, v. 22, pp. 396-405, 2000. 
[9] BONALDI, F., SCHAEFFER, L. "Processo de moldagem de pós metálicos por injeção - uma revisão", Engenharia (São Paulo), v. 589, pp. 164-167, 2008.

[10] PARUCKER, M.L., KLEIN, A.N., et al., "Desenvolvimento de liga sinterizada de níquel por moldagem de pós por injeção”, Revista Matéria, v. 19, pp. 218-227, 2014.

[11] CHOI, J., LIU, H., LEE, W., et al., "Densification and microstructural development during sintering of powder injection molded Fe micro-nanopowder”, Powder Technology, v. 253, pp. 596-601, 2015.

[12] SHONGWE, M.B., DIOUF, S., DUROWOJU, M.O., et al., "Effect of sintering temperature on the microstructure and mechanical properties of $\mathrm{Fe} 30 \% \mathrm{Ni}$ alloys produced by spark plasma sintering", Journal of Alloys and Compounds, v. 649, pp. 824-832, 2015.

[13] SCIREA, R. F., VIEIRA JUNIOR, L. E., RODRIGUES NETO, J. B., et al. “Otimização reológica de suspensões aquosas de óxido de ferro (III)”, Revista Matéria, v. 20, pp. 185-192, 2015. 